\title{
Reliability of Early and Final Counts in Cold and Cool Germination Tests for Predicting Maize Seed Vigour
}

\author{
Enrico Noli ${ }^{1}$, Emma Beltrami, Emanuela Casarini, Giovanni Urso, Sergio Conti \\ Seed Research and Testing Laboratory (LaRAS), Department of Agroenvironmental Sciences \\ and Technologies, University of Bologna \\ Viale Fanin 40, 40127 Bologna, Italy
}

Received: 24 April 2010. Accepted: 6 October 2010.

\begin{abstract}
Cold test (CT) is widely used in maize for predicting field performance in early sowing, even though it is rather labour intensive and requires almost two weeks to complete. The objective of this work was to examine alternative procedures to CT suitable for routine testing. Standard germination (SG), CT and cool germination (CG) were carried out on 24 maize lots chosen with high $(>85 \%)$ SG. For the three tests, besides the final count of normal seedlings, early counts of germinated seeds were made. Lots were evaluated in two field trials (six replicates each) sowed at a very early and early date. For all the laboratory traits, the differences among lots were significant and attained higher values in the early counts compared to the final ones. Moreover, the correlations were high between early counts performed during the three tests but were in general lower between early and final counts. Early counts showed lower correlations with field performance than the final ones, except for the count at $144 \mathrm{~h}$ during CG that attained a correlation level with field emergence $(r=0.81)$ similar to the final counts of CG and CT. Nonetheless, the evaluation of seedling vigour during the final count of CT showed the highest predictive value of field performance. All the laboratory measures were in close agreement with field performance when the latter was evaluated under less unfavourable conditions.
\end{abstract}

Key-words: early sowing, field emergence, maize, seed vigour testing.

\section{Introduction}

The widely adopted practice of performing maize planting in a season still characterised by rather low soil temperatures, that corresponds in the Po Valley to the second half of March, requires the availability of high vigour seed (i.e. able to perform satisfactorily in suboptimal conditions). In order to accurately estimate the quality of maize seed lots, several laboratory tests had been previously compared at LaRAS for their ability to predict field performance (Lovato and Balboni, 1997; Noli et al., 2008). In these investigations, the cold test (CT) in sand proved superior to other procedures, as mean germination time (MGT), complex stress vigour test (CSVT), accelerated ageing (AA) and soak test (ST), showing the highest correlation with field emergence in early sowing.

Recent papers (Matthews and Khajeh Hosseini, 2006; Ilbi et al., 2009; Khajeh Hosseini et al., 2009; Matthews et al., 2010) have suggested other procedures as potential routine vigour tests for maize such as mean germination time (MGT) or early counts of physiological germination measured at suboptimal cool germination (CG) or near to optimal temperatures in soil or in paper towels. The determination of the MGT, requiring several daily counts is, however, rather time-consuming and does not appear to be a practicable procedure in routine testing. On the other hand, a single count of germinated seeds in an early stage would combine the advantage of a simple, non-subjective assess-

* Corresponding Author: Tel. +39 051 2096253; Fax: +39 051 2096252. E-mail address: enrico.noli@unibo.it 
ment with that of a short testing time. In particular, the efficiency of an early count-based method could be further increased if, in the future, an automated scoring of germinated seed was adopted.

In the present work, some methods for assessing seed quality (SG, CT and CG) are compared for their ability to predict field emergence, also evaluating for each procedure the reliability of early counts. Moreover, the number of high vigour seedlings was determined at the final count of CT, according to the current practice in commercial testing at the Seed Research and Testing Laboratory (LaRAS) of the University of Bologna.

\section{Materials and methods}

\section{Seed lots}

Twenty-four maize seed samples were chosen among materials submitted by K.W.S. ITALIA SPA to LaRAS for laboratory analyses (standard germination and cold test) in fall-winter 2008. The choice was based on standard germination higher than $85 \%$ and a wide range of cold test results (from less than 80 to higher than $95 \%$ ). All seed lots had been treated with the same fungicides (Metalaxyl + Fludioxonil + Procloraz) and were produced in the 2007 and 2008 growing seasons. All samples were stored at $15{ }^{\circ} \mathrm{C}$ and $45 \%$ relative humidity before use.

\section{Seed Quality Determinations}

All the laboratory tests and the field evaluations here reported (Table 1) were conducted from March (field experiments) to November 2009. Three procedures were performed: standard germination, cold test in sand and cool germination.

Standard germination (SG) was carried out in sand at $25{ }^{\circ} \mathrm{C}$ with seeds sown at a dept of $1.5 \mathrm{~cm}$, and normal seedling evaluation after 168 h $(7 \mathrm{~d})$, according to ISTA (2006). Two additional counts of seedlings emergence were performed after 72 and $78 \mathrm{~h}$, respectively. A seedling was considered emerged when the coleoptile was at least $0.5 \mathrm{~cm}$ above the surface of the sand.

Cold test (CT) was conducted according to Noli et al. (2008) on a sand substrate for $168 \mathrm{~h}$ at $10{ }^{\circ} \mathrm{C}$ followed by $144 \mathrm{~h}$ at $25{ }^{\circ} \mathrm{C}$; two additional counts of seedling emergence, evaluated as above, were performed at 216 and $222 \mathrm{~h}$ after sowing (i.e. 48 and $54 \mathrm{~h}$ after the beginning of the warm period of germination). At the end of the test period, besides the standard seedling evaluation, normal seedlings were classified either as high- or low-vigour (HV and LV, respectively). We classified as $\mathrm{HV}$ the seedlings whose second leaf reached at least $2 / 3$ of the length of the first leaf.

Cool germination (CG) was performed in rolled paper towels at a constant temperature

Table 1 . Tests performed and traits measured in the laboratory and in the field.

\begin{tabular}{llll}
\hline & Acronym & Test conditions & Trait \\
\hline $\begin{array}{l}\text { Laboratory tests } \\
\text { Standard }\end{array}$ & SG $72 \mathrm{~h}$ & $72 \mathrm{~h}$ at $25{ }^{\circ} \mathrm{C}$ & N. of emerged seedlings \\
Germination & SG $78 \mathrm{~h}$ & $78 \mathrm{~h}$ at $25{ }^{\circ} \mathrm{C}$ & $\begin{array}{l}\text { N. of emerged seedlings } \\
\text { N. of normal seedlings }\end{array}$ \\
& SG Normal & $168 \mathrm{~h}$ at $25{ }^{\circ} \mathrm{C}$ & \\
Cold Test & CT $216 \mathrm{~h}$ & $168 \mathrm{~h}$ at $10{ }^{\circ} \mathrm{C}+48 \mathrm{~h}$ at $25{ }^{\circ} \mathrm{C}$ & N. of emerged seedlings \\
& CT $222 \mathrm{~h}$ & $168 \mathrm{~h}$ at $10{ }^{\circ} \mathrm{C}+54 \mathrm{~h}$ at $25^{\circ} \mathrm{C}$ & N. of emerged seedlings \\
& CT Normal & $168 \mathrm{~h}$ at $10{ }^{\circ} \mathrm{C}+144 \mathrm{~h}$ at $25{ }^{\circ} \mathrm{C}$ & N. of normal seedlings \\
& CT HV & $168 \mathrm{~h}$ at $10{ }^{\circ} \mathrm{C}+144 \mathrm{~h}$ at $25{ }^{\circ} \mathrm{C}$ & N. of high vigour seedlings \\
Cool & CG $72 \mathrm{~h}$ & $72 \mathrm{~h}$ at $13{ }^{\circ} \mathrm{C}$ & N. of germinated seeds \\
Germination & CG $96 \mathrm{~h}$ & $96 \mathrm{~h}$ at $13{ }^{\circ} \mathrm{C}$ & N. of germinated seeds \\
& CG $120 \mathrm{~h}$ & $120 \mathrm{~h}$ at $13{ }^{\circ} \mathrm{C}$ & N. of germinated seeds \\
& CG $144 \mathrm{~h}$ & $144 \mathrm{~h}$ at $13{ }^{\circ} \mathrm{C}$ & N. of germinated seeds \\
& CG Normal & $312 \mathrm{~h}$ at $13{ }^{\circ} \mathrm{C}$ & N. of normal seedlings \\
\hline Field plot trials & FE & Field & N. of emerged seedlings \\
& MET & Field & Mean emergence time from sowing \\
& PW & Field & Plant fresh weight \\
\hline
\end{tabular}


of $13{ }^{\circ} \mathrm{C}$, according to the procedure used by Khajeh Hosseini et al. (2009), with final count after $312 \mathrm{~h}$ (13 d). Physiological germination (2 mm-protruded radicle) was assessed at 72,96 , 120 and $144 \mathrm{~h}$. The time intervals of early counts for all the test procedures were defined based on our preliminary experiments (unpublished data) and/or expert suggestions (Dr Stan Matthews, personal communication).

The above experiments were carried out considering four replicates of 50 seeds for SG and CT, and eight replicates of 25 seeds for CG.

\section{Field experiments}

Two field trials were carried out in spring 2009, at the experimental farm of the University of Bologna at Cadriano (Po Valley, Northern Italy) on a silt-loam soil, according to a complete randomised block design with six replications. Plots consisted of a single row $2.5 \mathrm{~m}$ long including 50 seeds. The two experiments were sown in adjacent fields on 17 and 26 March, respectively, using a single-row sowing machine at a depth of about $5 \mathrm{~cm}$ with spacing of $40 \mathrm{~cm}$ between rows. Soil temperatures and rainfall were monitored for the entire duration of the experiments. Temperatures were measured every 30 min using three thermocouple probes connected to a CR10X datalogger (Campbell Scientific) placed on the experimental area. Immediately after planting, the plots of both experiments were irrigated with $250 \mathrm{~m}^{3}$ of water ha-1.

Field emergence (FE) was recorded daily, starting when the first seedling was visible until completion and considering as emerged those seedlings whose coleoptile reached a height of $1.5 \mathrm{~cm}$. The mean emergence time was calculated as MET $=\Sigma\left(n_{i} d_{i}\right) / \Sigma n_{i}$, where $n_{i}$ is the number of seedlings emerged in day $i$ and $d_{i}$ is the number of days from the sowing to time $i$.
Final counts were performed on 23 and 24 April, when 198 and $192^{\circ} \mathrm{Cd}$ (calculated according to Noli et al., 2008) had accumulated from planting for the first and the second trials, respectively. The seedlings were then cut at the ground level and the fresh weight per plot (PW) was measured.

\section{Statistical analysis}

Analysis of variance (ANOVA) of the values expressed as percentages for both laboratory and field trials was carried out after arcsine transformation of the data; angular values were also utilised to calculate linear correlation coefficients.

The statistical analyses of the field trials were first conducted separately for each experiment and a combined analysis over the two sowing dates was then carried out. The $\mathrm{F}$ ratio of the ANOVA was performed considering the seed lot and sowing date as fixed and random effects, respectively (mixed model).

\section{Results}

\section{Laboratory experiments}

For all the tests, highly significant effects $(P \leq$ 0.001 ) of lot samples were detected (Table 2). It is worth noting that the differences among lots proved to always be higher in the early than in the final counts, as evidenced by the standard deviations among sample means. In particular, for SG the widest range (data not shown) was attained at $72 \mathrm{~h}$ (from 18.59 to $89.0 \%$ ), for CT at $216 \mathrm{~h}$ (from 6.0 to $75.5 \%$ ) even though just slightly higher than at $222 \mathrm{~h}$ and for $\mathrm{CG}$ at 96 $\mathrm{h}$ (from 3.5 to $95.5 \%$ ). It can be underlined, however, that also the error coefficient of variation (CV) was always higher in the early than

Table 2. Statistical parameters calculated for the laboratory traits: mean values are calculated on raw data, the other parameters on angular transformed data.

\begin{tabular}{|c|c|c|c|c|c|c|c|c|c|c|c|c|}
\hline & \multicolumn{3}{|c|}{ SG } & \multicolumn{4}{|c|}{$\mathrm{CT}$} & \multicolumn{5}{|c|}{ CG } \\
\hline & $72 \mathrm{~h}$ & $78 \mathrm{~h}$ & Normal & $216 \mathrm{~h}$ & $222 \mathrm{~h}$ & Normal & $\mathrm{HV}$ & $72 \mathrm{~h}$ & $96 \mathrm{~h}$ & $120 \mathrm{~h}$ & $144 \mathrm{~h}$ & Normal \\
\hline Mean (\%) & 55.7 & 73.8 & 93.6 & 41.1 & 63.1 & 91.8 & 81.5 & 6.0 & 44.1 & 83.6 & 92.3 & 91.3 \\
\hline F ratio & & & & & & & & & & & & \\
\hline among samples & $* * *$ & $* * *$ & $* * *$ & $* * *$ & $* * *$ & $* * *$ & $* * *$ & $* * *$ & $* * *$ & $* * *$ & $* * *$ & $* * *$ \\
\hline $\mathrm{CV}(\%)$ & 14.7 & 10.5 & 6.5 & 19.7 & 11.3 & 6.6 & 8.1 & 79.7 & 21.2 & 10.0 & 8.9 & 9.2 \\
\hline SD among samples & 15.4 & 13.1 & 4.4 & 15.5 & 15.2 & 6.0 & 9.9 & 12.3 & 18.6 & 10.6 & 8.2 & 6.4 \\
\hline
\end{tabular}

***: significant at $\mathrm{P} \leq 0.001$. 
in the final counts, thus indicating a lower precision associated to those estimates. The higher $\mathrm{CV}$ for the final count observed in CG (9.2) as compared to SG and CT (6.5 and 6.6, respectively) does not imply a lower precision of the first test, but is just attributable to the lower number of seeds used in each replicate: in fact, the values would be identical if the $\mathrm{CV}$ were calculated on the mean basis (3.3 for all the tests; data not shown). Therefore, the three procedures should be considered equivalent for their precision when an equal number of seeds per lot were tested.

Regarding the final counts of normal seedlings, the mean values were rather high and similar for the three tests $(93.6,91.8$ and $91.3 \%$ for SG, CT and CG, respectively); analogously, very small differences were observed among the three procedures considering the best performing lots, whereas differences were sizeable among the minimum values (85.5, 78.5 and $66.0 \%$ for SG, CT and CG, respectively; data not shown).

Table 3 shows the correlation coefficients among laboratory traits. Considering the normal seedlings, the highest correlation was found between the two tests conducted at suboptimal temperatures, i.e. CT and CG $(r=0.82)$; highly significant coefficients were also observed between these and SG ( $r=0.70$ for the correlation with CT and 0.63 with CG). Counts of physiological germination performed with the different methods in the early stages were almost always significantly correlated. In particular, the $r$ values ranged from 0.71 to 0.75 for the rela- tions between SG and CT, from 0.50 to 0.79 for those between SG and CG and from 0.38 and 0.73 between CT and CG. The correlations between CG counts at $72 \mathrm{~h}$ and the early SG and CT counts were, as a tendency, lower compared to counts at later stages. Very high values were observed for the correlations between early counts for both SG and CT ( $r=0.95$ and 0.96 , respectively) as expected due to the short time interval between their measurement; in this respect, considering the four early counts carried out during the CG test, it is worth noting how the correlations decreased as the interval between counts increased. Early scored data were not significantly correlated with final counts of normal seedlings at the end of the standard period for the SG test ( $r=0.15$ and 0.28$)$, whereas they showed higher and significant correlations for CT ( $r=0.61$ and 0.72$)$ and for CG, at least for the counts at 120 and $144 \mathrm{~h}(r=0.73$ and 0.86).

\section{Field experiments}

The main statistical parameters regarding the traits measured in the field are shown in Table 4. Even in this case, highly significant differences among lots were detected for all the traits in both trials. Nevertheless, the relative performance was different in the two experiments as evidenced by the interaction "seed lot $\mathrm{x}$ sowing date" which was highly significant $(P \leq 0.001)$ for MET and PW and significant $(P \leq 0.05)$ for FE. However, the $\mathrm{F}$ ratio of the lot mean square tested on interaction mean square reached the

Table 3. Correlation coefficients among laboratory traits.

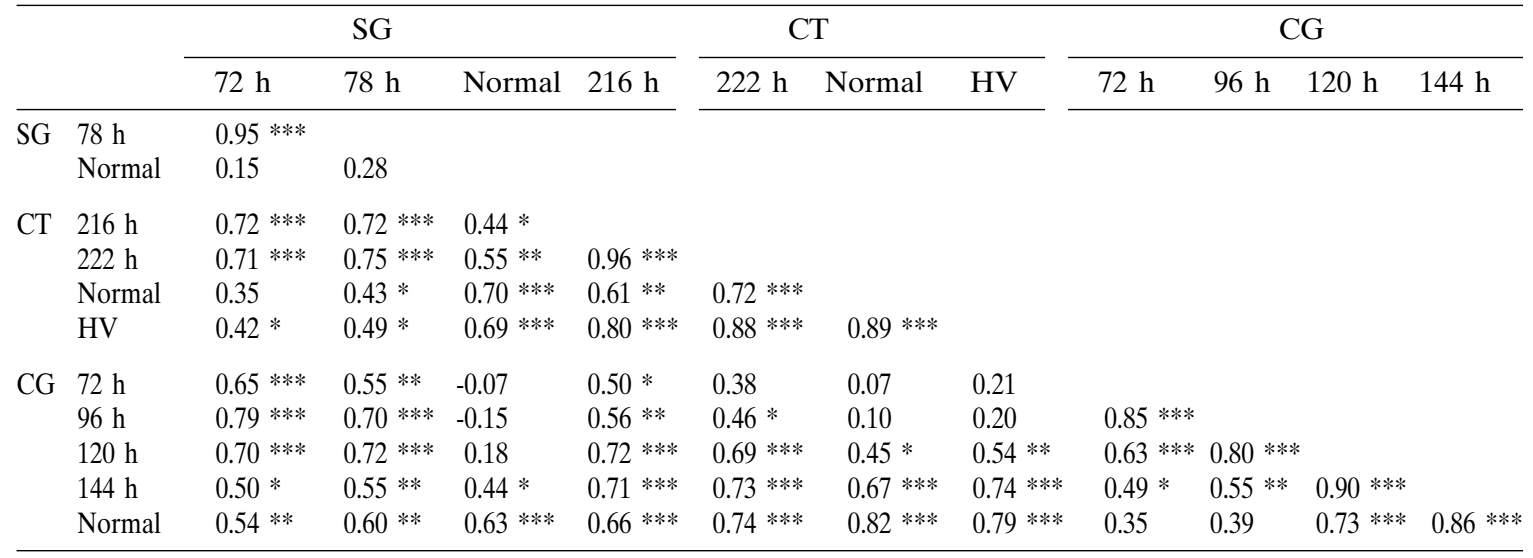

*, **, ***: significant at $P \leq 0.05,0.01$ and 0.001 , respectively. 
Table 4. Statistical parameters calculated for the field traits: mean values are calculated on raw data, the other parameters on angular transformed data.

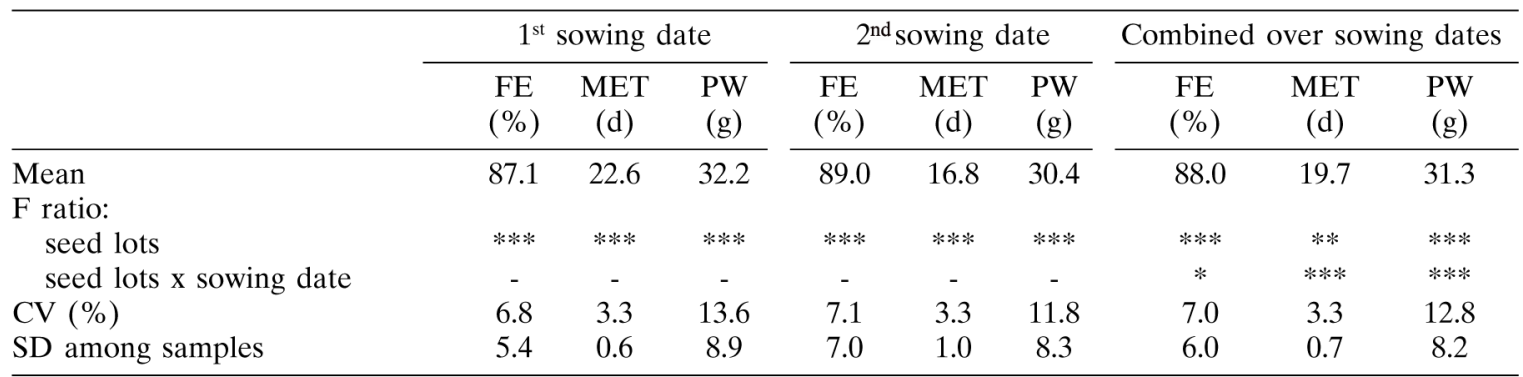

*, **, ***: significant at $P \leq 0.05,0.01$ and 0.001 , respectively.

significance level for all the traits. The $r$ correlation coefficients between data collected in the two adjacent trials were 0.85 for FE, 0.60 for MET and 0.84 for PW (data not shown).

The differences between trials were, above all, remarkable for MET which was delayed about six days in the first as compared to the second sowing date, and rather small for PW and FE. As to MET, the difference is the result of the environmental conditions during the period preceding emergence. In particular, as shown in Figure 1, in the first trial soil temperatures for some days after sowing were rather low with mean values close to the base temperature $\left(8{ }^{\circ} \mathrm{C}\right)$ and minimum values below 5 ${ }^{\circ} \mathrm{C}$, whereas in the second trial the minimum temperatures were always higher than $10^{\circ} \mathrm{C}$, except for two days after sowing. Overall, during the first and second experiments soil temperatures averaged 13.4 and $14.8{ }^{\circ} \mathrm{C}$, respectively. On the other hand, the slightly superior value of
$\mathrm{PW}$ in the first trial can be at least partially due to the higher ${ }^{\circ} \mathrm{Cd}$ accumulated at harvest.

\section{Predictive ability of the laboratory tests}

Correlation coefficients between laboratory and field measurements are reported in Table 5. The comparison of $r$ values between the normal seedlings counted with the three procedures and FE indicates the equivalence of the two tests conducted at suboptimal temperature (CT and $\mathrm{CG})$ that proved superior, although not significantly, to SG in predicting field performance $(r$ $=0.81$ and 0.82 vs. 0.59 , considering the mean values over sowing dates). For CT, slightly higher correlations were obtained when $\mathrm{HV}$ instead of normal seedlings were taken into account ( $r$ $=0.84$ vs. 0.81 ).

Regarding the early counts, those measured at SG conditions showed levels of correlation with FE lower than those obtained with the final ones, having reached the significance level only in the second sowing. Conversely, fairly

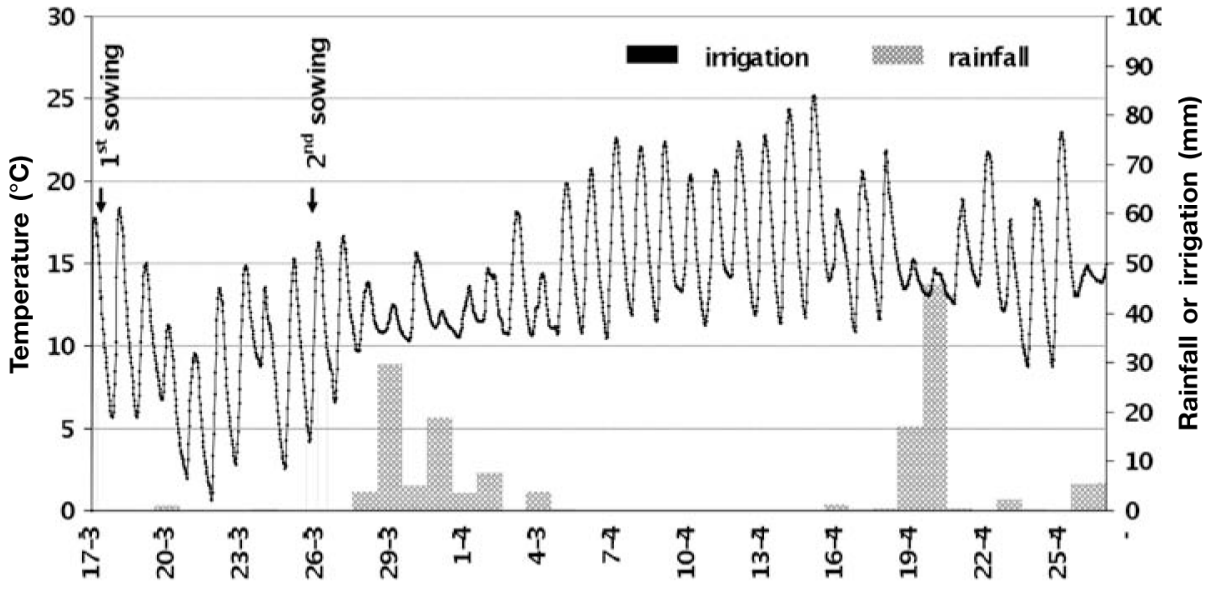

Figure 1. Soil temperature, irrigation and rainfall during the two field emergence trials. 
Table 5. Correlation coefficients between laboratory and field traits.

\begin{tabular}{|c|c|c|c|c|c|c|c|c|c|c|c|c|c|}
\hline \multicolumn{14}{|c|}{ Laboratory traits } \\
\hline & & \multicolumn{3}{|c|}{ SG } & \multicolumn{4}{|c|}{$\mathrm{CT}$} & \multicolumn{5}{|c|}{$\mathrm{CG}$} \\
\hline \multicolumn{2}{|c|}{ Field traits } & $72 \mathrm{~h}$ & $78 \mathrm{~h}$ & Normal & $216 \mathrm{~h}$ & $222 \mathrm{~h}$ & Normal & HV & $72 \mathrm{~h}$ & $96 \mathrm{~h}$ & $120 \mathrm{~h}$ & $144 \mathrm{~h}$ & Normal \\
\hline $1^{\text {st }}$ sowing & $\mathrm{FE}$ & 0.25 & 0.31 & $0.42 *$ & $0.61 * *$ & $0.63 * * *$ & $0.70 * * *$ & $0.74 * * * *$ & 0.08 & 0.24 & $0.62 * *$ & $0.73 * * *$ & $0.71 * * *$ \\
\hline \multirow{2}{*}{ date } & MET & 0.02 & -0.07 & -0.36 & -0.40 & $-0.42 *$ & $-0.48 *$ & $-0.60 * *$ & 0.10 & 0.08 & -0.31 & $-0.45 *$ & -0.37 \\
\hline & PW & 0.07 & 0.18 & $0.45 *$ & $0.48 *$ & $0.55 * *$ & $0.61 * *$ & $0.72 * * *$ & -0.09 & -0.08 & 0.40 & $0.60 * *$ & $0.53 * *$ \\
\hline $2^{\text {nd }}$ sowing & $\mathrm{FE}$ & 0.36 & $0.41 *$ & $0.68 * * *$ & $0.69 * * *$ & $0.73 * * *$ & $0.85 * * *$ & $0.87 * * *$ & 0.24 & 0.26 & $0.63 * * *$ & $0.82 * * *$ & $0.85^{* * *}$ \\
\hline \multirow{2}{*}{ date } & MET & -0.30 & -0.38 & $-0.61 * *$ & $-0.73 * * *$ & $-0.74 * * *$ & $-0.65 * * *$ & $-0.79 * * *$ & -0.23 & -0.30 & $-0.66 * * *$ & $-0.80 * * *$ & $-0.75 * * *$ \\
\hline & PW & 0.24 & 0.36 & $0.68 * * *$ & $0.69 * * *$ & $0.76 * * *$ & $0.72 * * *$ & $0.86 * * *$ & 0.09 & 0.11 & $0.55 * *$ & $0.74 * * *$ & $0.70 * * *$ \\
\hline \multirow{3}{*}{$\begin{array}{l}\text { Combined } \\
\text { over sowing } \\
\text { dates }\end{array}$} & FE & 0.32 & 0.38 & $0.59 * *$ & $0.68 * * *$ & $0.71 * * *$ & $0.81 * * *$ & $0.84 * * *$ & 0.18 & 0.26 & $0.65 * * *$ & $0.81 * * *$ & $0.82 * * *$ \\
\hline & MET & -0.19 & -0.29 & $-0.57 * *$ & $-0.67 * * *$ & $-0.68 * * *$ & $-0.65 * * *$ & $-0.79 * * *$ & -0.11 & -0.17 & $-0.59 * *$ & $-0.74 * * *$ & $-0.67 * * *$ \\
\hline & PW & 0.16 & 0.28 & $0.59 * *$ & $0.61 * *$ & $0.68 * * *$ & $0.69 * * *$ & $0.82 * * * *$ & 0.00 & 0.01 & $0.49 *$ & $0.69 * * *$ & $0.64 * * *$ \\
\hline
\end{tabular}

$*, * *, * * *$ : significant at $P \leq 0.05,0.01$ and 0.001 , respectively.

good indications were provided by early counts of CT $(r>0.60)$, even though in this case as well with a lower correlation as compared to that of final counts.

In the case of CG, no correlations were observed for the first two counts with FE, and only a moderate correlation was observed for the third $(r \geq 0.62)$. Notably, the correlation shown by counts at $144 \mathrm{~h}$, whose $r$ coefficients reached levels very close to those obtained with final counts, was very high.

The laboratory tests conducted at suboptimal temperatures were also better predictors of MET than SG, as evidenced by the correlations based on final counts of normal seedlings. In particular, the best indicator proved to be the final count of $\mathrm{HV}$ seedlings performed with CT $(r=-0.79$, on a mean basis). Moderate correlations with MET were also observed considering both early counts performed with CT and, even more, the one at $144 \mathrm{~h}$ during CG. In this respect, it is worth noting that the early counts performed with SG were not informative of the emergence rate.

The observations made regarding the prediction of FE based on laboratory tests hold also for PW, a trait that summarises both the number and the degree of development of emerged plants; however, the level of correlation attained with PW was generally lower than that with FE. Also for PW, the highest correlations were obtained with HV.

Furthermore, it should be stressed that the comparison of correlation coefficients between laboratory data and field traits measured in the two experiment shows without exception high- er values in the second than in the first sowing date.

Figure 2 shows the relationships of the laboratory data that proved to be more informative (those obtained with CT and CG) and field emergence. It should be firstly considered that the maximum predictive power of a laboratory procedure is attained when the $a$ and $b$ regression coefficients are equal to 0 and 1 , respectively, and $\mathrm{R}^{2}$ is equal to 1 (ideal test). When $b$ approximates to 1 , values of $a$ superior or inferior to 0 mean an underestimate or an overestimate of the field performance based on laboratory data, respectively. Values of $b$ inferior to 1 indicate a wider range for the laboratory data than for FE (high discriminatory capacity of the test), and vice versa if superior to 1 .

The comparison of the values of regression coefficients and of $\mathrm{R}^{2}$ relative to the two sowing dates indicates as a tendency, for all the laboratory data, a lower predictive power of field emergence under more critical conditions (higher deviations from ideal values). The tests that proved more informative of the behaviour in the field were the final counts of normal seedlings of both CT and CG. The regression lines of the FE in second sowing over CG fit the ideal line well with parameters $a=0$ and $b$ $=1$ (the dotted diagonal in the figures), thus meaning that this laboratory result provides a good prediction of FE.

The count of HV seedlings performed in CT provided a good discrimination among lots. However, the differences between the mediumand the well-performing lots were superior to those actually observed in the field. Overall, this 

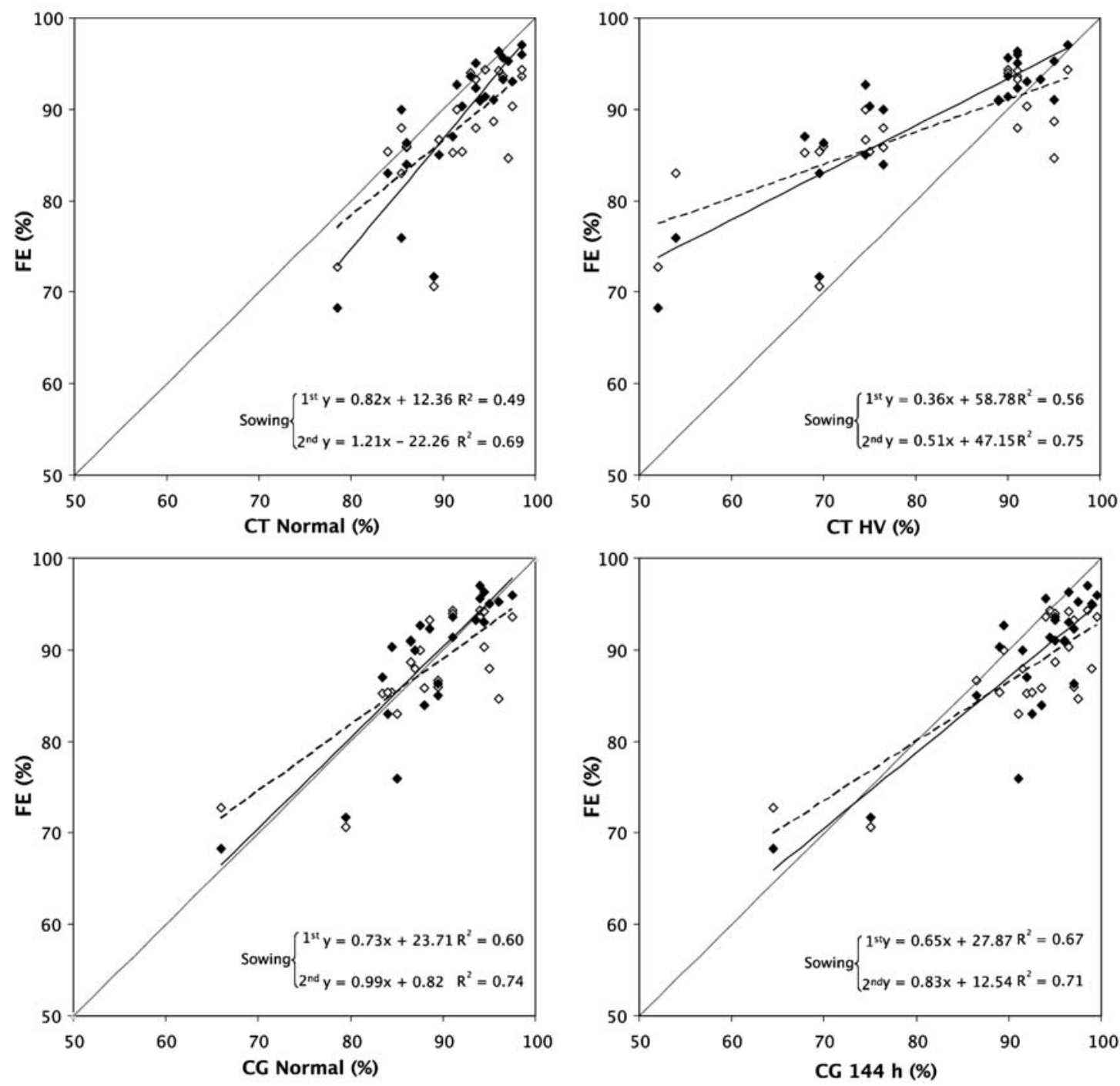

Figure 2. Relationships between field emergence, in two sowing dates, and performance in laboratory tests: (a) CT Normal, final count of normal seedlings; (b) CT HV, final count of high vigour seedlings; (c) CG Normal, final count of normal seedlings; (d) CG $144 \mathrm{~h}$, germination count at $144 \mathrm{~h}$. Empty symbols and dashed lines refer to the $1 \mathrm{st}$ sowing date, filled symbols and solid lines to the 2 nd sowing date.

test proved rather severe, showing a tendency to underestimate FE, particularly for the lots characterised by a poorer performance. On the contrary, the count at $144 \mathrm{~h}$ during CG, that does not consider abnormal seedlings, shows some tendency to overestimate FE, particularly for the lots with higher germination.

\section{Discussion}

For a comparison of the suitability of laboratory tests as routine tools for the evaluation of seed vigour, different aspects should be taken into account. Besides the reliability of the test in predicting the field behaviour of the seed lot which represents the most important feature, other practical aspects that ultimately determine the time and cost of testing should be considered.

Among the tests available to evaluate seed vigour in maize, CT with soil is the most accepted and widely used in routine practice, being based on the simultaneous application of abiotic (cold) and biotic (soil pathogens) stress- 
es which characterise the seedbed conditions in early sowing. However, the wide variability of soil microflora in different environments can often limit the reproducibility and the predictive power of laboratory results (Burris and Navratil, 1979). On the other hand, in a very broad comparative study, Nijenstein and Kruse (2000) observed that soil played a minor role in the CT results, whereas other authors (Loeffler et al., 1982; Martin and O'Neil, 1987) reported that CT performed in paper towels with or without soil produced comparable results. Moreover, Lovato and Balboni (1997) found slightly higher correlations with field emergence of CT in sand as compared to the one with soil. Although superior to other vigour tests such as MGT at $25^{\circ} \mathrm{C}, \mathrm{CSVT}, \mathrm{AA}$ and ST in predicting field performance (Lovato and Balboni, 1997; Martin et al., 1988; Noli et al., 2008), the CT, particularly when conducted in soil or sand, is a rather labour-intensive procedure and as an alternative, a CG test at suboptimal temperature (13 ${ }^{\circ} \mathrm{C}$ ) had been suggested (Van de Venter and Lock, 1991).

The CG was assayed more recently by Ilbi et al. (2009) that reported good correlations $(r>0.75)$ with $\mathrm{FE}$ at least when relatively high temperatures $\left(15\right.$ and $\left.18{ }^{\circ} \mathrm{C}\right)$ were utilised. In the present work, if the final measures are considered, the $\mathrm{CG}$ test at $13{ }^{\circ} \mathrm{C}$ showed a predictive value of $\mathrm{FE}$ as well as of MET and PW very similar to that of CT. Furthermore, for both $\mathrm{CT}$ and CG the levels of correlation with FE and MET were rather close to those between the measurements of the same field traits in adjacent trials, which could be taken as a reference value.

However, it is worth noting that both CT and CG showed lower correlations with field data measured in the first sowing, characterised by lower soil temperatures, than in the second one. This seems to indicate that both tests may be less suitable to predict seed behaviour in rather critical conditions.

Matthews and Khajeh Hosseini (2006) reported significant correlations between mean germination time (MGT) at $13{ }^{\circ} \mathrm{C}$ in paper towels and final emergence or MET in soil in the growth chamber; similar correlations were found by Khajeh Hosseini et al. (2009) with field emergence. In the latter work, considering that frequent counts are needed to determine the
MGT, the Authors suggested that early counts of physiological germination (such as after 6 days at $13{ }^{\circ} \mathrm{C}$ ) could be a more convenient and easy to standardise procedure to be used in the seed testing routine. Our data measured at 144 h (= 6 days) during CG at $13{ }^{\circ} \mathrm{C}$ evidenced a correlation with $\mathrm{FE}$ of very similar level to that shown by final count, whereas the correlation with MET or with PW was slightly higher. Due to the shorter testing time (about half with respect to that required for the final count), this procedure seems an interesting option to estimate seed vigour for commercial laboratories. However, for its slight tendency to overestimate FE, particularly for the best performing samples, this method can not accurately predict the behaviour in the field. Nevertheless, based on the regression analysis on the combined data of the two trials we can infer that a threshold level of $90 \%$ of FE, could be obtained with lots showing a CG at $144 \mathrm{~h}$ higher than $95 \%$. Earlier counts performed during CG showed lower or even non-significant correlations with field traits, whereas those performed during CT were as informative as the final ones as regards MET but slightly inferior for predicting FE. Moreover, the time-saving in this case was quite limited (3 days) with respect to the standard CT method and hence their utilisation is of scarce interest.

A better prediction of field performance, at least in terms of rate of emergence (MET) and seedling development (PW), has been obtained considering the frequency of $\mathrm{HV}$ seedlings in the final count of CT. This additional measurement that as a tendency provided the best prediction of PW can be carried out with a limited increase in time and cost and could complement the standard evaluation providing a more efficient assessment of field stand.

\section{Acknowledgment}

The authors thank the K.W.S. ITALIA SPA for supplying the seed used in this research.

\section{References}

Burris J.S., Navratil R.J. 1979. Relationship between laboratory cold-test methods and field emergence in maize inbreds. Agron. J., 71:985-988. 
Ilbi H., Kavak S., Eser B. 2009. Cool germination test can be an alternative vigour test for maize. Seed Sci. Technol., 37:516-519.

ISTA 2006. International Rules for Seed Testing. Zurich, Switzerland, ISTA.

Khajeh Hosseini M., Lomholt A., Matthews S. 2009. Mean germination time in the laboratory estimates the relative vigour and field performance of commercial seed lots of maize (Zea mays L.). Seed Sci. Technol., 37:446-456.

Loeffler N.L., Meier J.L., Burris J.S. 1982. Comparison of three cold test procedures for use in drying studies. Iowa Seed Sci., 4, 1:5-6.

Lovato A., Balboni N. 1997. Seed vigour in maize (Zea mays L.): two-year laboratory and field test compared. Ital. J. Agron., 1:1-6.

Martin B.A., O'Neil M. 1987. Laboratory tests for the assessment of vigor in maize. In: Proc. $9^{\text {th }}$ Annu. Seed Tech. Conf., Ames, IA. 24-25 Feb. Seed Sci. Ctr., I.S.U., Ames, IA, 208-220.

Martin B.A., Smith O.S., O’Neil M. 1988. Relationships between laboratory germination tests and field emergence of maize inbreds. Crop Sci., 28:801-805.

Matthews S., Khajeh Hosseini M. 2006. Mean germination time as an indicator of emergence performance in soil of seed lots of maize (Zea mays). Seed Sci. Technol., 34:339-347.

Matthews S., El-Khadem R., Casarini E., Khajeh Hosseini M., Nasehzadeh M., Wagner M.-H. 2010. Rate of physiological germination compared with the cold test and accelerated ageing as a repeatable vigour test for maize. Seed Sci. Technol., 38:379-389.

Nijenstein J.H., Kruse M. 2000. The potential for standardisation in cold testing of maize (Zea mays L.). Seed Sci. Technol., 28:837-851.

Noli E., Casarini E., Urso G., Conti S. 2008. Suitability of three vigour tests procedures to predict field performance of maize seed in early sowing. Seed Sci. Technol., 36:168-176.

Van de Venter H.A., Lock H.W. 1991. A comparison of seed vigour tests for maize (Zea mays L.). S. Afr. J. Plant Soil, 8:1-5. 
